the time was ripe to knock ecological and genetical heads together for the grand reckoning, to force distinguished strangers to present and write joint papers, breaking down what J. Turner points out as 'cognitive particularism' in science: the inability on the part of one group to conceive that what the opposition is saying makes any sense whatsoever! By this device, no one individual could hide for long behind the comfort of esoteric jargon or enjoy the luxury of personally imploding on a microspecialization. Refreshingly, we are treated to honest dialogue, some of it still smouldering from fires not quite extinguished (J. Turner: "My own view is that there is no good evidence in favour of the neutral theory"), but all with the sense of urgency that the two disciplines need to merge, with more than a backward glance to the approaching charge of the new breed of molecular ecology imperialists (well represented here by M. Kreitman, P. Young and T. Burke).

A Who's Who of leading investigators spiritedly lay out their working philosophies with R. May, B. Clarke, B. Shorrocks, S. Stearns, P. Harvey, B. Levin. M. Begon, M. Hassell, J. Endler, R. Koehn and W. Watt and many other friends and foes taking as much interest in each other's perspectives as they can currently muster. One major gap in the listings is the absence of house-trained molecular biologists with first-hand experience of the fluidity of the genome and its contributions per se to standing levels of molecular diversity at the population level. Many molecular probes are not well-behaved mendelian elements obligingly evolving in a clock-like manner: they have a life of their own which we ignore at our peril.

W. Provine, A. Cain, S. Berry and A. Bradshaw provide the historical background, showing that blame for the schism that almost isolated the study of evolution from the college of scientific disciplines has to be laid at the door of some influential theoretical geneticists. Wrapped within the $a$ priori belief in universal selective determinism they fought against neutrality and the molecular clock, constraints, trends and stasis, sympatric speciation, genetic revolutions, chaos, nonadaptive evolution, the stochasticity of metapopulations, probability refuges, hierarchies of selection, reaction norms, exaptations, suggestive directed mutagenesis, and (I would add) the ubiquitous mechanisms of genomic flux that underpin evolution by means of molecular drive. Wielding their equations and algorithms, they flay all such phenomena either to marginalize them or tame them within the high moral ground of panselectionist theory. "Ecology is what organisms do when they are doing nothing interesting" might sound amusing from the mouth of E. B. Ford but is disastrous as a scientific attitude (realized or not) in those who assumed the mantle of Darwin.

There is a constructive place for theory in all sciences but if evolutionary theory is to be brought back to Earth, then a deep re-examination of its assumptions and parameters is in order; "How actually" must replace "how possibly" (as R. Sibly and J. Antonovics point out) no matter how tangled, complex, irrational and haphazard real organisms are in their real environments. M. Feder and W. Watt, in particular, provide a comprehensive and persuasive pointer on how to reach this "Holy Grail".

Evolutionary theory needs to move on from naive caricature and application of darwinian selection in the same way that physics moved on from newtonian mechanics. By embracing the internal dynamics of the genome and the external dynamics of the ecology, there is hope for it yet.

G. A. Dover is in the Department of Genetics, University of Leicester, Leicester LE1 7RH, UK.

\title{
Imperfect unities of knowledge
}

\section{John Ziman}

Common Sense, Science and Scepticism: A Historical Introduction to the Theory of Knowledge. By Alan Musgrave. Cambridge University Press: 1993. Pp. 310. £35, \$54.95 (hbk); £12.95, \$17.95 (pbk).

Reading the Book of Nature: An Introduction to the Philosophy of Science. By Peter Kosso. Cambridge University Press: 1992. Pp. 198. £22.95, \$34.95 (hbk); $£ 7.95, \$ 10.95$ (pbk).

The Disorder of Things: Metaphysical Foundations of the Disunity of Science. By John Dupré. Harvard University Press: 1993. Pp. 308. \$35, £27.95.

THE 'Two Cultures' thesis of the $1960 \mathrm{~s}$ challenged the narrowness of science education. So science students were coaxed into courses on the history and philosophy of science as a natural bridge into the humanities and as a background to their own specialized studies. This didn't work.

One reason was that history and philosophy of science, as normally taught, turned out to be just as specialized and dry-as-dust as any scientific discipline. Another was that it all seemed very remote from what the students were learning to do in their science courses. Instead of illuminating scientific practice, philosophy merely made it seem vaguely questionable.

The first two of these books are typical products of this educational fiasco. Alan Musgrave does the conventional round of gurus - Aristotle, Descartes, Kant et al. - and their epistemological doctrines - scepticism, empiricism, rationalism and so on. For no obvious reason he then takes the popperian exit, which he labels "fallibilist realism". Surely, for a science student, that's like Omar Khayyam in his youth, going out "by that same door as I went in".

On the other wing, it's all 'common sense', with no damned nonsense about rigour. That's obvious from Peter Kosso's title, which he keeps repeating as if he meant it. In the seventeenth cenury people genuinely believed in a benevolent, omniscient Author. Nowadays, we describe scientists as writing books about nature rather than reading a pre-ordained text. Tush!

With the philosophy of knowledge in such doldrums, monocultured scientists do better to concentrate on the philosophy of nature. Instead of asking questions such as 'how is it we know?' and 'how do we know it?', it is more fruitful to ask 'what is it we know?' and 'what do we know about it?'. John Dupré's book is original, lucid and confident, without being eccentric, polemical or arrogant. It deserves close attention.

To the average scientist, especially on the physical side, the unity of science seems indisputable. But it is clearly a metaphysical principle, beyond scientific verification. Dupré's thesis is both an assertion of how the world is and a denial that science constitutes, or could ever constitute, a single unified project.

His central target is obviously reductionism. Dupré takes this to mean the belief that the world can be classified hierarchically, and that the laws operating at higher levels can be derived for those at lower levels. If this were completely valid, then the world described or explored by science would be united by the laws of the lowest level. This is why some theoretical physicists look forward confidently to the discovery of a 'Theory of Everything'. But even if complete physicalism could never rule in practice, piecewise reductionism is often presented as desirable, and feasible in principle, at every interface between levels - molecule to atom, cell to molecule, organism to cell and so on.

Dupré disputes this on deep-rooted theoretical grounds. $\mathrm{He}$ is not talking about the practical limitations of insufficient computer power, inadequate knowl- 
edge of the relevant properties or our recent recognition of the characteristically chaotic phenomena that can arise even in deterministic systems. His argument is complex, with many subtleties to explore. But it seems to me that it is built around the following point, which he illustrates by an ecological example.

Suppose that we are looking for the scientific laws governing the respective abundances of hares and lynxes, and wish to 'reduce' these to the laws describing the behaviour of individual animals. We know that lynxes depend on hares for their food, and have certain capabilities for hunting, killing and eating them. We may also know, from very detailed observation, about the strategies used by hares to avoid capture, their breeding habits and so on. Nevertheless, no amount of this 'lower level' knowledge would be sufficient to determine the probability of capture in such encounters. This is a statistical property of the hare-lynx system, describing the outcomes of innumerable such encounters. Although it is functionally dependent on the behavioural characteristics of the species, it is defined only as the result of observations averaged over the populations in question. The reductionist project fails. The required property of individuals is not meaningful except in the context of scientific discourse at the population level. So it cannot be used to rewrite this discourse in the scientific terminology of individual behaviour. Ecology is not 'just' zoology on a larger scale.

Many important philosophical themes intersect in this focal area. Dupré first considers 'essentialism', as it arises typically in biological systematics. For example, are there certain essential features differentiating one species from another? What distinguishes hares from rabbits, which are also food for lynxes? Do the features used by taxonomists have any relevance to their capacity for escaping capture? Ecologically, should they be lumped together as a single population or treated separately?

It is often thought that sex is an essential property of an individual organism: should the males and females of these various species be considered as distinct natural kinds when it comes to hunting or being hunted? Dupré argues persuasively that sexual and gender differences do not support ethnographic, ecological or ethological generalizations, in humans or other animals. This is a socio-political insight that he rightly underlines in his final chapter on science and values.

Physicists and chemists are often taught, most unwisely, that biological taxonomy is akin to stamp collecting. It is a foundation law of physics that all electrons are identical; in chemistry, all

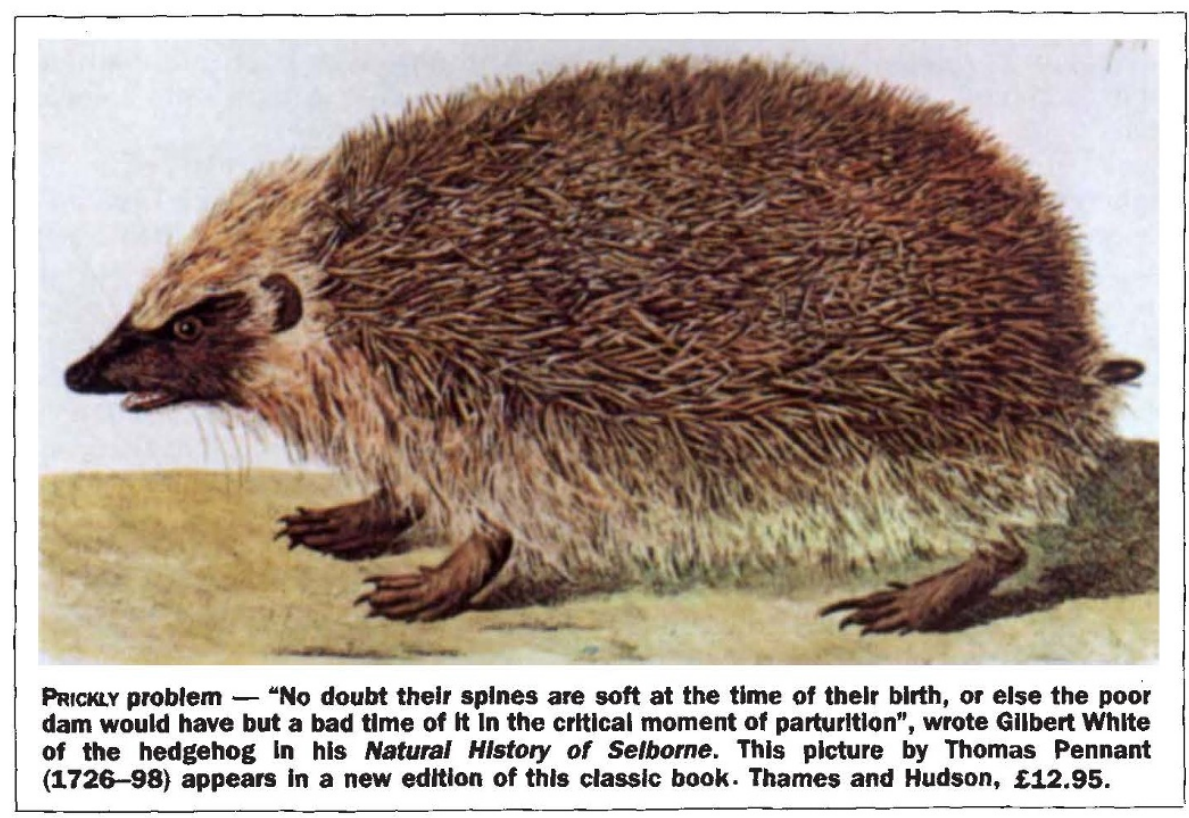

nuclei of a given isotope are strictly interchangeable. The forthcoming 'Grand Unified Theory' will claim to describe 'everything' in terms of absolutely essential properties such as mass, charge and quark colour. Dupré might note that the operating context of the 'lowest level' has been expensively and lovingly contrived to evince precisely these properties. There is no empirical support for the belief that this downward analysis can be reversed to synthesize upwards through biology, psychology and human history.

That would require an account of all the causes that generate phenomena. Dupré shows that causality for the events at a particular level cannot be attributed exclusively to entities and events at the next lower level. Even the notion of 'levels' here is suspect. Suppose we are trying to prove that the behaviour of an organism is 'caused' by what goes on among its cells. How does this apply to a molecular pheromone causing sexual behaviour in a social situation? Ambiguities of categorization reduce the reductionist account to a shambles of improvization.

The notion of 'probabilistic causality' is no help. In fact, as Dupré remarks "our intuitions about causality ... are derived wholly from the macrolevel" and yet when we want to give a complete causal story we are usually forced to retreat to the microlevel, where quantum uncertainty vitiates those intuitions. Speaking of causality, reflect on the thought that "what is problematic about humans is not that they are exceptions to an otherwise seamless web of causal connection, but that they are extraordinarily dense concentrations of causal capacity in a world in which such order is in short supply". Such insights are potent weapons.
Note that this is not mystical obscurantism. There is no appeal to supernatural, immaterial influences. It is not a debunking, relativizing attack on the philosophical ethos of the scientific enterprise. Apart from some justified scorn at the unrealized pretensions of certain disciplines, such as population genetics and macro-economics, Dupré accepts, indeed celebrates, many of the achievements of science. He approves of unifying developments that link previously disconnected parts of science or extend the range of theories or techniques.

All he asks for is a clear realization that reductive analysis is essential for an understanding of how a kind of phenomenon is possible, but tells us little about the actual course of events. For that reason "reductionism is a local condition of scientific research, not an irresistible tide sweeping the whole of science into an increasingly orderly pattern".

Dupré insists that there is no general scientific method, process or attitude. Science should be thought of as "a loose and heterogeneous collection of more or less successful investigative practices varying from the highly plausible to the quite incredible, and from the extremely valuable to the entirely pernicious". He pins down the notion of the unity of science as a form of scientism appropriate only to a Utopia or to totalitarianism. He notes that "paradoxically, with the disunity of science comes a kind of unity of knowledge". That is why, to my mind, this is just the kind of philosophical teaching that is needed to close the gap between the two cultures. Here, surely, is the door through which we should, when young, have come out.

John Ziman is at 27 Little London Green, Oakley, Aylesbury, Buckinghamshire HP18 9QL, UK.

NATURE · VOL $362 \cdot 15$ APRIL 1993 